\title{
Zoneamento de risco de incêndios florestais para a bacia hidrográfica do Córrego do Petiço - Botucatu (SP)
}

\author{
Fire risk zoning in forest for the watershed of Petiço Stream - Botucatu (SP)
}

\author{
Riesgo de incêndios forestales aplicables a la cuenca hidrográfica del Arroyo Petiço - \\ Botucatu (SP)
}

Felipe de Souza Nogueira Tagliarini Mestrando em Agronomia - Energia na Agricultura, UNESP/Botucatu, Brasil. felipe_tagliarini@hotmail.com

\author{
Aline Kuramoto Gonçalves \\ Doutoranda em Agronomia - Energia na Agricultura, UNESP/Botucatu, Brasil. \\ aline587@gmail.com
}

\section{RESUMO}

O presente trabalho apresenta o desenvolvimento de uma metodologia para o zoneamento de risco de incêndio para a bacia hidrográfica do Córrego do Petiço, localizado no município de Botucatu/SP. A utilização do Sistema de Informação Geográfica foi utilizado para a elaboração dos mapas de riscos referentes as classes de altimetria, declividade, face de exposição do terreno, influência da hidrografia, influência de estradas e uso ocupação do solo. Os fatores foram integrados e todas as variáveis receberam o mesmo peso e a sobreposição dessas informações gerou o mapa de zoneamento de risco de incêndios florestais da bacia. Os resultados apontaram o risco de incêndio 'Baixo' 1,49\%, 'Moderado' 44,47 \%, 'Alto' 53,53 \% e 'Muito Alto' 0,51 \% do total da área da bacia, não foi observada a classe de risco 'Extremo' na área. As classes de risco 'Alto' e 'Muito Alto' merecem maior atenção, se somadas, pois representam mais da metade da área da bacia e para tais classes é necessário um planejamento e outras práticas preventivas ao combate de incêndios.

PALAVRAS-CHAVE: Incêndios. Sistema de Informação Geográfica. Zoneamento.

\begin{abstract}
The present work introduces the development of a methodology for zoning the fire risk to the watershed of Petiço stream, located in the municipality of Botucatu/SP. The Geographical Information System was used for the preparation the risk maps relative of altimetry, slope, terrain display face, influence of hydrographic, influence of roads, use and occupation of land. The factors were integrated and all variables are given the same weight, the overlap of the information generated the map of zoning risk of forest fires in the watershed. The results indicate the risk of fire 'Low' $1.49 \%$ 'Moderate' $44.47 \%$, 'High' $53.53 \%$ and 'Very High' $0.51 \%$ of the total area of the watershed, was not observed the risk class 'Extreme' in the area. Risk classes 'High' and 'Very High' deserve greater attention, if added together, they represent more than half area of the watershed and for such classes are necessary planning and other preventive practices to fire fighting.
\end{abstract}

KEY WORDS: Fire Risk. Geographical Information System. Zoning.

\section{RESUMEN}

El presente trabajo apresenta dessarollar la metodologia de zonificación riesgo de incendios forestales aplicables a la cuenca hidrográfica del Arroyo Petiço, localizado en el município de Botucatu/SP. El Sistema de Información Geografica se ha utilizado para elaborar los mapas de riesgo referentes de las clases de altimetria, declividad, exposición del terreno, influencia de la hidrografia, influencia de caminho y a uso y ocupación del suelo. Los factores 
fueron integarse y para toda las variables recibieron el mismo peso, la sobreposición de información generó el mapa de riesgo de incendios forestales de la cuenca. Los resultados indicaron los riegos de incendios 'Bajo' 1,49 \%, 'Moderado' 44,47\%, 'Alto' 53,53 \% y 'Muy Alto' 0,51 \% en la totalidad de área de la cuenca, no se observó la classe de riesgo 'Extremo' en la área. Las clases de riesgo 'Alto' y 'Muy Alto' requieren mayor atención, sumadas, ya que representan más de la mitad de la área de la cuenca y como las clases es necessário un planificación y demás medidas preventivas de luchar contra incendios.

PALABRAS-CLAVE: Incendios. Sistema de Información Geografica. Zonificación.

\section{Introdução}

$\mathrm{O}$ incêndio ocasionado em áreas agrícolas, matas nativas e em florestas sem controle e malconduzida podem ocasionar em prejuízos e a degradação ambiental. A ação do fogo sobre essas áreas gera prejuízos as características do solo, a fauna e atmosfera, sendo responsável pela degradação de toda a cobertura vegetal, agrícola ou florestal.

Diversas medidas vêm sendo adotada para combater e minimizar o avanço ao risco de incêndios nessas áreas, porém, para alcançar a maior eficiência é preciso um planejamento estratégico.

Neste contexto, o zoneamento do risco de incêndio ou mapas de risco de incêndios tem possibilitado a oferecer suporte ao combate aos incêndios. Este zoneamento permite visualizar áreas com maior probabilidade de ocorrência de incêndios, suporte em decisões quanto à distribuição de recursos e equipamentos destinados à prevenção e supressão do fogo (FERRAZ; VETTORAZZI, 1998; BATISTA, 2000; RIBEIRO et al., 2008).

Segundo Ferraz e Vettorazzi (1998) e Batista (2000) o zoneamento ou mapa de risco pode ser obtido por meio da sobreposição de mapas temáticos que representam os fatores de risco em um Sistema de Informação Geográfica (SIG) permite trabalhar dados com rapidez no processamento e o dinamismo no cruzamento de informações, tornando esta técnica indispensável em estudos deste tipo.

Os fatores que explicam a propagação e a ignição dos incêndios são diversos, tais como: as características dos combustíveis, condições meteorológicas, fontes de ignição e topografia.

A característica do combustível depende da estrutura e composição da vegetação, aliadas aos fatores antropogênicos (MARQUES et al., 2011). Outro fator importante de ignição é a influência das atividades humanas, que aumentam o risco de incêndios nas vizinhanças das redes de estradas e áreas urbanas (CARDILLE et al., 2001).

Os principais fatores utilizados nesse estudo para estabelecer os níveis de risco de incêndios são: declividade, orientação das encostas, altimetria, distribuição do sistema viário, hidrografia e uso do solo.

Com as informações oferecidas pelos mapas de risco, várias medidas podem ser tomadas para reduzir a ocorrência de incêndios, como por exemplo: maior vigilância nas áreas de risco, restrição do acesso a esses locais, construção de aceiros preventivos e reorganização das práticas de manejos.

\section{Objetivo}


O objetivo deste trabalho foi elaborar o zoneamento de risco de incêndios na bacia hidrográfica do Córrego do Petiço, por meio do uso do Sistema de Informação Geográfica (SIG), que permite realizar análises complexas e integrar um banco de dados para auxiliar nas tomadas de decisão quanto ao melhor manejo dos recursos naturais.

\section{Materiais e métodos}

\section{1. Área de estudo}

A microbacia hidrográfica do Córrego Petiço (Figura 1) localiza-se na região Centro-Oeste do Estado de São Paulo, no município de Botucatu, possui uma área total de 3385,20 ha, com situação definida nas coordenadas geográficas $48^{\circ} 20^{\prime} 23^{\prime \prime}$ a $48^{\circ} 15^{\prime} 12^{\prime \prime}$ de longitude W Gr. e $22^{\circ} 51^{\prime} 51^{\prime \prime}$ a $22^{\circ} 46^{\prime} 54^{\prime \prime}$ de latitude $S$ (TAGLIARINI; RODRIGUES; GARCIA, 2014).

Figura 1: Localização da bacia do Córrego Petiço, Botucatu-SP.

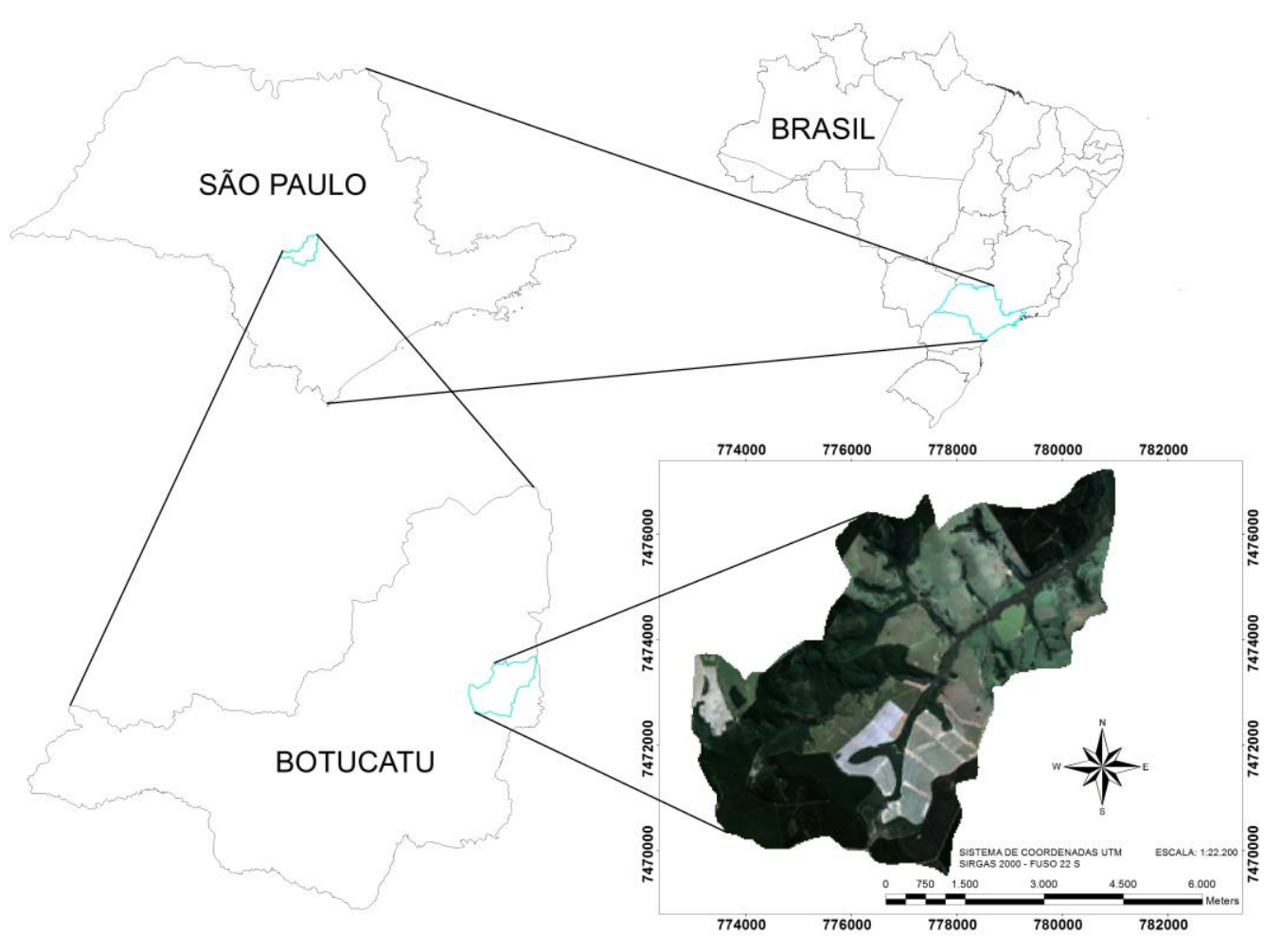

A classificação climática de Köppen, para a área é temperado quente (mesotérmico) úmido, do tipo Cwa, com chuvas no verão e seca no inverno, possui precipitação média anual de 1358,6 mm e temperatura média anual de 20,7 ㄷ (CENTRO DE PESQUISAS METEOROLÓGICAS E CLIMÁTICAS APLICADAS À AGRICULTURA - CEPAGRI, 2016).

O uso do solo na bacia, de acordo com Tagliarini, Rodrigues e Garcia (2014), tem por destaque, o reflorestamento que ocupa cerca de 1040,36 ha $(30,73 \%)$, seguido por pastagens com 939,8 
ha $(27,76 \%)$, vegetação nativa com 739,36 ha $(21,84 \%)$ e citrus com área de 392,27 ha $(11,61$ $\%)$, essas que são as principais atividades de uso e ocupação do solo encontrados no Córrego do Petiço.

\subsection{Informações cartográficas e imagens de satélite}

As informações referentes as curvas de nível e hidrografia (rede de drenagem e nascentes), foram obtidas de cartas topográficas do IGC (Instituto Geográfico e Cartográfico do Estado de São Paulo), em escala 1:10.000 e equidistância entre as curvas de nível de 5 metros, disponíveis para download no site GeoPortal do IGC.

Posteriormente, no ambiente do SIG (Sistema de Informações Geográficas) ArcGIS 10.3, foi gerado o modelo digital de superfície TIN (Triangulated Irregular Network) a partir da interpolação das curvas, que permitiu a obtenção dos mapas de altimetria, declividade em porcentagem e faces de exposição do terreno. O mapa referente a influência da hidrografia foi obtido através de Buffers da rede de drenagem e nascentes.

Já as informações referentes ao uso e ocupação do solo e influência de estradas, foram obtidas por meio de imagens do satélite LANDSAT-8, sensor OLI (Operational Land Imager), bandas 2, 3, 4, 5 e 6 (respectivamente azul, verde, vermelho, infravermelho próximo e infravermelho médio) de 30 metros de resolução espacial, e banda 8 (pancromática) que possuí 15 metros de resolução espacial, da órbita 220, ponto 76, com data de registro de 13 de agosto de 2015, obtidas para download no catálogo de imagens do U.S. Department of the Interior/U.S. Geological Survey. No SIG após a composição das bandas BGR (2, 3 e 4) e falsa cor (6, 5 e 4), foi realizada a fusão com a banda pancromática para melhorar a resolução do produto final, permitindo a melhor identificação dos usos do solo e das estradas, assim facilitando a construção de polígonos para cada uma das classes. O mapa de influência de estradas foi obtido por Buffers das estradas, similar ao de hidrografia.

\subsection{Metodologia}

Os fatores ambientais são considerados de acordo com as condições de riscos locais e com o critério que mais se ajusta a cada situação de risco (RIBEIRO et al., 2008). No caso do presente trabalho os fatores selecionados para gerar o mapa de risco foram: altimetria, declividade, faces de exposição do terreno, influência da hidrografia, influência da rede de drenagem e uso e ocupação do solo, seguindo as metodologias propostas por Batista, Oliveira e Soares (2002); Ribeiro et al. (2008); Nicolete e Zimback (2013).

Cada um dos fatores foi distribuído em cinco classes, que correspondem aos riscos 'Baixo', 'Moderado', 'Alto', 'Muito Alto' e 'Extremo'. Para cada uma das classes, atribuiu-se um peso indicando o nível de risco, o qual foi a base para a álgebra de mapas. Posteriormente, houve uma sobreposição de todos os fatores para geração do mapa final de zoneamento do risco de incêndios florestais. 


\subsection{Mapas de risco}

\subsubsection{Altimetria}

Baixas elevações têm a tendência de apresentar estações de risco de incêndios mais longas que altas elevações (NICOLETE; ZIMBACK, 2013). A variação da altitude representa uma variável ambiental que influencia o risco de incêndio devido a sua relação com a umidade relativa do ar (RIBEIRO et al., 2008). Segundo Salas e Chuvieco (1994), conforme se aumenta a altitude, ocorre um decréscimo da temperatura e uma elevação na umidade relativa, diminuindo assim o risco de incêndios florestais. Os valores de altimetria e seus respectivos pesos podem ser observados na Tabela 1.

Tabela 1: Classificação de risco quanto à altimetria.

\begin{tabular}{ccc}
\hline Classes altimétricas & Risco & Peso \\
\hline$<600 \mathrm{~m}$ & Extremo & 5 \\
$600-900 \mathrm{~m}$ & Muito Alto & 4 \\
$900-1200 \mathrm{~m}$ & Alto & 3 \\
$1200-1500 \mathrm{~m}$ & Moderado & 2 \\
$>1500 \mathrm{~m}$ & Baixo & 1 \\
\hline
\end{tabular}

Fonte: RIBEIRO et al. (2008).

\subsubsection{Declividade}

A propagação do fogo em aclives (áreas de maior inclinação) é superior ao de declives (áreas de menor inclinação), portanto, as áreas mais declivosas são consideradas de maior risco, pois a transferência de calor é facilitada à medida que o grau de inclinação aumenta, aumentando a velocidade de propagação do fogo (FERRAZ; VETTORAZZI, 1998; SOARES; BATISTA, 2007). A Tabela 2 relaciona a declividade do terreno em função da sua influência na taxa de risco de incêndio.

Tabela 2: Classificação de risco quanto à declividade do terreno.

\begin{tabular}{ccc}
\hline Classes de declividade & Risco & Peso \\
\hline$<15 \%$ & Baixo & 1 \\
$15-25 \%$ & Moderado & 2 \\
$25-35 \%$ & Alto & 3 \\
$35-45 \%$ & Muito Alto & 4 \\
$>45 \%$ & Extremo & 5 \\
\hline
\end{tabular}

Fonte: Adaptado de SOARES; BATISTA, (2007); RIBEIRO et al. (2008).

\subsubsection{Faces de exposição do terreno}

Esse fator tem importância sobre a disponibilidade energética para a redução da umidade dos materiais combustíveis. De acordo com Soares e Batista (2007) no hemisfério Sul os raios solares incidem mais sobre as faces do terreno voltadas para o Norte, fazendo com que essa 
face de exposição receba e transmita mais energia que qualquer outra exposição do terreno, aumentando assim o risco de incêndios. Na Tabela 3, pode-se observar a classificação das faces de exposição do terreno na bacia hidrográfica e seus respectivos pesos.

Tabela 3: Classificação de risco quanto às faces de exposição do terreno.

\begin{tabular}{ccc}
\hline Classes de exposição do terreno & Risco & Peso \\
\hline SE / S / SW & Baixo & 1 \\
E & Moderado & 2 \\
NE & Alto & 3 \\
NW / W & Muito Alto & 4 \\
N & Extremo & 5 \\
\hline
\end{tabular}

Fonte: RIBEIRO et al. (2008).

\subsubsection{Influência da hidrografia}

No risco de incêndios florestais a proximidade com a rede de drenagem e corpos d'água pode ser positiva ou negativa. Segundo Ribeiro et al. (2008) a influência pode ser positiva por servirem como uma barreira à propagação do fogo, porém negativa por tais áreas serem propícias a visitação humana para atividades de recreação, turismo, pesca, camping e até atividades de cunho religioso.

Dessa forma, foi estabelecido um raio de influência de 50 metros em toda a rede de drenagem, corpos d'água e nascentes da bacia, valores acima desse raio foram considerados sem influência. Os valores de influência e seus respectivos pesos podem ser observados na Tabela 4.

Tabela 4: Classificação de risco quanto à proximidade da hidrografia.

\begin{tabular}{ccc}
\hline Classes de influência da hidrografia & Risco & Peso \\
\hline Sem Influência (acima de $50 \mathrm{~m}$ ) & Ausente & 0 \\
Sob Influência (até $50 \mathrm{~m}$ ) & Presente & 1 \\
\hline
\end{tabular}

Fonte: Adaptado de RIBEIRO et al. (2008).

\subsubsection{Influência de estradas}

A malha viária seja através de rodovias, estradas vicinais, carreadores e/ou até mesmo trilhas são elos interligados que permitem o acesso a dada localidade e também o escoamento do sistema produtivo no meio rural, permitindo a exploração mais eficiente da região. Porém, estradas podem ser um fator desencadeante seja devido a incêndios criminosos; prática de cultos religiosos; incêndios causados por cigarros e fogueiras, além de outras ocorrências, portanto devem ser consideradas quando se realiza uma análise de zoneamento de riscos de fogo (FERRAZ; VETTORAZZI, 1998; SILVEIRA; VETTORAZZI; VALENTE, 2008; RIBEIRO et al., 2008). 
Seguindo a metodologia proposta por Ribeiro et al. (2008), o raio de influência de estradas foi de 50 metros, para as estradas vicinais e carreadores existentes na área de estudo. Esse valor, como pode ser observado na Tabela 5 , foi considerado devido às estradas internas de propriedades pertencentes à bacia do Córrego do Petiço possuírem pouco tráfego e também por não haver rodovias na área de estudo, onde o raio de risco é maior devido ao seu tráfego intenso.

Tabela 5: Classificação de risco quanto à proximidade de estradas.

\begin{tabular}{ccc}
\hline Classes de influência de estradas & Risco & Peso \\
\hline Sem Influência (acima de $50 \mathrm{~m}$ ) & Ausente & 0 \\
Sob Influência (até $50 \mathrm{~m}$ ) & Presente & 1 \\
\hline
\end{tabular}

Fonte: RIBEIRO et al. (2008).

\subsubsection{Uso e ocupação do solo}

O tipo de uso e ocupação do solo influencia o comportamento do fogo de várias maneiras, sendo esse fator de grande importância na determinação do risco de ocorrência de incêndios florestais. A variação na presença ou ausência de cobertura vegetal implica em mudanças de diversos aspectos relacionados com o comportamento do fogo, principalmente quanto ao material combustível e as condições microclimáticas que dado uso representa (BATISTA, 2000). A representação do uso e ocupação do solo também contribui para a determinação das atividades econômicas que têm potencial para o aumento do risco (NICOLETE; ZIMBACK, 2013). Na Tabela 6, pode-se observar os usos e ocupação do solo na bacia hidrográfica do Córrego do Petiço, bem como seus respectivos pesos.

Tabela 6: Classificação de risco quanto ao uso e ocupação do solo.

\begin{tabular}{ccc}
\hline Classes de uso e ocupação do solo & Risco & Peso \\
\hline Corpos d'água / Várzea / Erosão / Solo Exposto & Baixo & 1 \\
Quintais / Edificações & Moderado & 2 \\
Citrus & Alto & 3 \\
Vegetação Nativa & Muito Alto & 4 \\
Pastagem / Reflorestamento & Extremo & 5 \\
\hline
\end{tabular}

Fonte: Adaptado de RIBEIRO et al. (2008); SILVEIRA; VETTORAZZI; VALENTE, (2008); NICOLETE; ZIMBACK, (2013).

\subsection{Mapa de risco de incêndios}

Os mapas de altimetria, declividade, faces de exposição do terreno, influência da hidrografia, influência de estradas e uso e ocupação do solo foram integrados em uma somatória, em que todas as variáveis receberam o mesmo peso. O modelo utilizado pode ser observado na Equação 1, conforme proposto por Batista, Oliveira e Soares (2002). 


$$
\mathrm{RISCO}=\mathrm{AL}+\mathrm{DV}+\mathrm{FE}+\mathrm{IH}+\mathrm{IE}+\mathrm{UO}
$$

Onde: $\mathrm{AL}=$ risco quanto à declividade; $\mathrm{DV}=$ risco quanto à declividade; $\mathrm{FE}=$ Risco quanto às faces de exposição do terreno; $\mathrm{IH}$ = influência quanto à hidrografia; $\mathrm{IE}=$ Influência quanto às estradas; $\cup O$ = influência quanto ao uso e ocupação do solo.

O mapa de risco resultante traduz a influência dos seis fatores analisados sobre o risco e a propagação de incêndios na microbacia hidrográfica do Córrego do Petiço. As classes de risco foram consideradas de acordo com as potencialidades de ignição e se encontram relacionadas na Tabela 7.

Tabela 7: Classes de risco de incêndios florestais de acordo com o potencial de ignição.

\begin{tabular}{cc}
\hline Classes de peso & Classes de risco \\
\hline$<9$ & Baixo \\
$9-13$ & Moderado \\
$13-17$ & Alto \\
$17-21$ & Muito Alto \\
$>21$ & Extremo \\
\hline
\end{tabular}

Fonte: Adaptado de RIBEIRO et al. (2008).

\section{Resultados}

A partir da integração dos seis fatores de riscos resultou no mapa base de zoneamento de risco de incêndio florestal da bacia hidrográfica do Petiço, no qual proporcionou uma análise da situação de cada um dos fatores para práticas de manejo dos usos solo e prevenção de incêndios na área de estudo.

De acordo com Ribeiro et al. (2008) o uso do termo "incêndios florestais" é utilizado para definir fogo que se propaga livremente queimando qualquer tipo de material existente em uma dada área, seja ele de origem florestal ou não. Deste modo, o mapa de riscos de incêndios florestais obtidos neste trabalho resultou o risco de incêndio mesmo em uma área de citrus ou pastagem.

O mapa de zoneamento de risco de incêndio (Figura 2) resultou a classe de risco de fogo 'Alto' com maior representatividade, representado por 53,53 \% (1812,25 ha) do total da área da bacia, seguido pelas outras classes de risco que representam respectivamente 'Moderado' 44,47 \% (1505,49 ha), 'Baixo' 1,49 \% (50,28 ha) e 'Muito Alto' 17,18 \% (0,51 ha). De acordo com as variáveis consideradas não houve a classe de risco 'Extremo'. 
Figura 2: Zoneamento de risco de incêndio florestal para a bacia do Córrego Petiço, Botucatu-SP.

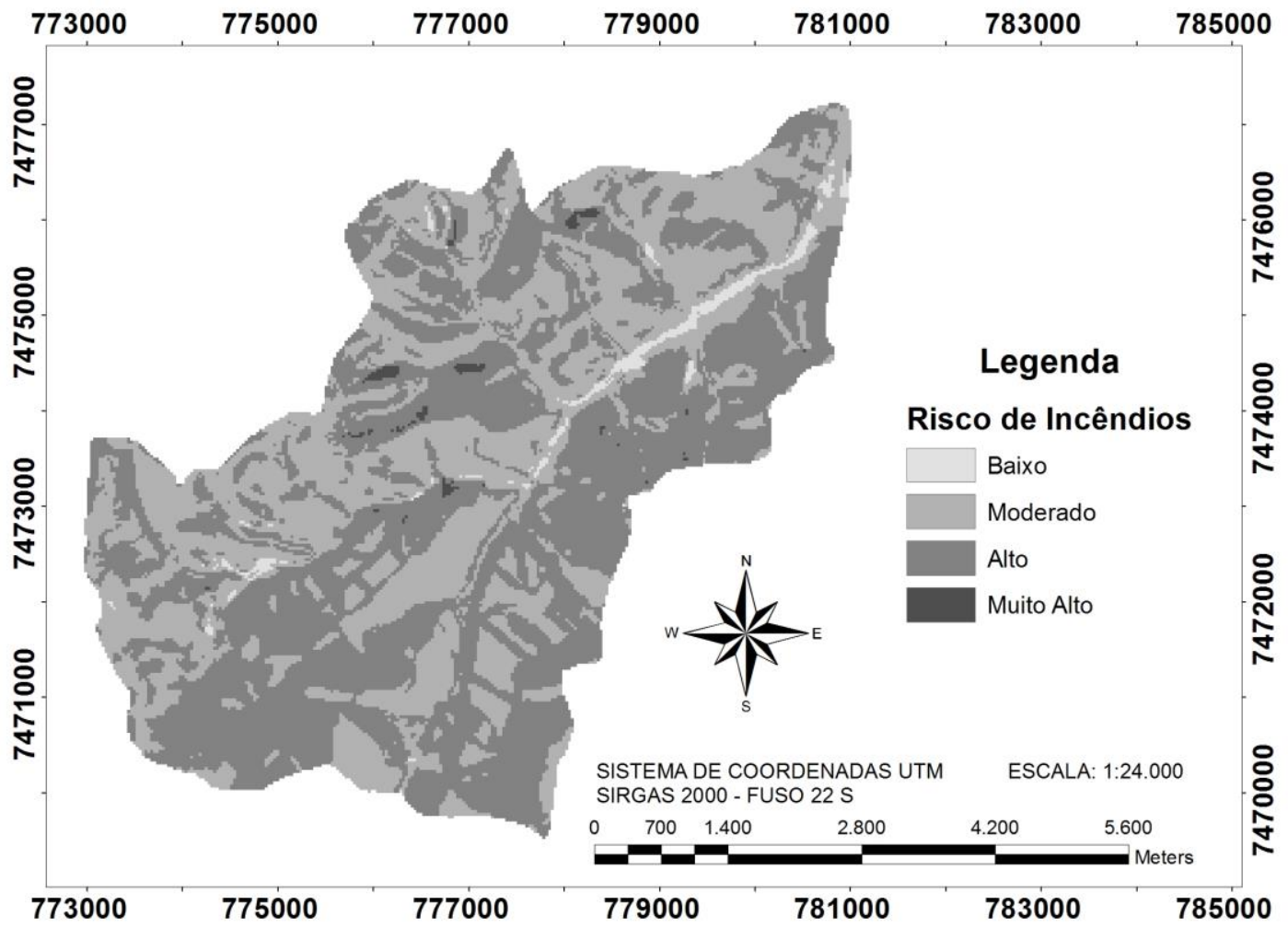

As classes de riscos de incêndios 'Alto' e 'Muito Alto' se somadas merecem maior preoucação por representar mais da metade da área da bacia, segundo Nicolete e Zimback (2013) para áreas com tais riscos deve haver um planejamento e outras práticas preventivas e uma logística para acesso e combate ao risco de incêndio, caso necessário.

Outra etapa importante foi quanto a avaliação dos pesos das classes de riscos de incêndios de cada um dos seis fatores, pois de acordo com Ferraz e Vettorazzi (1998) destacaram a importância de um banco de dados histórico de uma determinada área a risco de incêndio de forma a auxiliar e determinar áreas com indicio a ocorrencia de incêndios florestais. Como a bacia hidrográfica do Córrego do Petiço não possui um banco de dados histórico, a definição dos pesos dos fatores ficaram restritas aos dados da literatura.

\section{Conclusão}

A partir dos resultados encontrados nesse trabalho conclui-se que a bacia hidrográfica do Córrego do Petiço não possui no seu zoneamento a classe de risco 'Extremo', entretanto a maior parte da bacia tem a classe de risco 'Alto', representando mais da metade da área. As áreas mais propensas ao risco são ocupadas por reflorestamento e pastagem.

O mapa de zoneamento permitiu a integração dos fatores de riscos em um único mapa- base permitindo uma visão global de todos os fatores o que facilita a tomadas de decisões. A metodologia de integração e soma dos fatores de risco pode ser aplicada em outras áreas de 
estudos, de maneira a não existir uma série histórica sobre o zoneamento de risco de incêndios florestais, tendo sua importância para um melhor planejamento e manejo.

O uso de Sistema de Informação Geográfica mostrou eficiente para a elaboração dos mapas dos seis fatores de risco e o mapa de zoneamento, pois, permitiu uma rápida análise, visualização e a geração de mapas e tabelas.

\section{Referências bibliográficas}

BATISTA, A. C. Mapas de risco: uma alternativa para o planejamento de controle de incêndios florestais. Floresta, Curitiba, v. 30, n. 1, p. 45-54, 2000.

BATISTA, A. C.; OLIVEIRA, D. S.; SOARES, R. V. Zoneamento de risco de incêndios florestais para o estado do Paraná. Curitiba: FUPEF, 2002. 86 p.

CEPAGRI. Centro de Pesquisas Meteorológicas e Climáticas Aplicadas à Agricultura. Clima dos municípios paulistas - Botucatu. 2016. Disponível em: <http://www.cpa.unicamp.br/outras-informacoes/clima_muni_086.html>. Acesso em: 10 mar. 2016

CARDILLE, J. A.; VENTURA, S. J.; TURNER, M. G. Environmental and social factors influencing wildfires in the Upper Midwest, USA. Ecological Applications, Washington, v. 11, n. 1, p. 111-127, 2001.

FERRAZ, S. F. B.; VETTORAZZI, C. A. Mapeamento de risco de incêndios florestais por meio de sistema de informações geográficas (SIG). Scientia Forestalis, Piracicaba, v. 26, n. 53, p. 39-48, 1998.

IGC. Instituto Geográfico e Cartográfico do Estado de São Paulo. GeoPortal IGC. 2016. Disponível em: <http://geoportal.igc.sp.gov.br:8080/GeoPortalIGC/Internet/>. Acesso em: 15 jan. 2016.

MARQUES, S.; BORGES, J. G.; GARCIA-GONZALO, J.; MOREIRA, F.; CARREIRAS, J. M. B.; OLIVEIRA, M. M.; CANTARINHA, A.; BOTEQUIM, B.; PEREIRA, J. M. C. Characterization of wildfires in Portugal. European Journal Forest Research, Berlin, v. 130, p. 775-784, 2011.

NICOLETE, D. A. P.; ZIMBACK, C. R. L. Zoneamento de risco de incêndios florestais para a fazenda experimental Edgardia - Botucatu (SP), através de sistemas de informações geográficas. Revista Agrogeoambiental, Pouso Alegre, v. 5, n. 3, p. 55-62, 2013.

RIBEIRO, L. KOPROSKI, L. P.; STOLLE, L.; LINGNAU, C.; SOARES, R. V.; BATISTA, A. C. Zoneamento de riscos de incêndios florestais para a Fazenda Experimental do Canguiri, Pinhais (PR). Floresta, Curitiba, v. 38, n. 3, p. 561-572, 2008.

SALAS, J.; CHUVIECO, E. Geographic information systems for wildland fire risk mapping. Wildfire, Washington, v. 3, n. 2, p. 7-13, 1994.

SILVEIRA, H. L. F.; VETTORAZZI, C. A.; VALENTE, R. O. A. Avaliação multicriterial no mapeamento de risco de incêndios florestais, em ambiente sig, na bacia do Rio Corumbataí, SP. Revista Árvore, Viçosa, v. 32, n. 2, p. 259 268, 2008.

SOARES, R. V.; BATISTA, A. C. Incêndios Florestais: Controle, Efeitos e Uso do Fogo. Curitiba: UFPR, 2007. 264 p.

TAGLIARINI, F. S. N.; RODRIGUES, M. T.; GARCIA, Y. M. Uso de técnicas de geoprocessamento para o diagnóstico da ocupação do solo em áreas de preservação permanente de uma microbacia hidrográfica. Fórum Ambiental da Alta Paulista, Tupã, v. 10, n. 2, p. 313-325, 2014

USGS. U.S. Department of the Interior / U.S. Geological Survey. Browse Images. 2016. Disponível em: <http://glovis.usgs.gov/AboutBrowse.shtml>. Acesso em: 30 jan. 2016. 